- ORIGINAL ARTICLE

Volume 8 Issue 22016

DOI: 10.5959/eimj.v8i2.420

ARTICLE INFO

Submitted: 26-02-2016

Accepted: 10-04-2016

\section{Physicians' Self-assessment in Intercultural Clinical Communication in Jeddah, Saudi Arabia: A Pilot Study}

\author{
Hani Atwa, Asmaa Abdel Nasser \\ Medical Education Department, Faculty of Medicine, Suez Canal \\ University, Egypt
}

To cite this article: Hani Atwa, Asmaa Abdel Nasser. Physicians' self-assessment in intercultural clinical communication in Jeddah, Saudi Arabia: a pilot study. Education in Medicine Journal. 2016;8(2):15-26. DOI: 10.5959/eimj.v8i2.420

To link to this article: http://dx.doi.org/10.5959/eimj.v8i2.420

\begin{abstract}
Background: Physicians working with multicultural populations need to know how to determine the patients understanding of their illness. Physician working in Saudi Arabia must be aware of the diverse cultural and linguistic properties of people living there. They need to know how language and culture can influence clinical communication with patients and the way they provide them care. Aim: This study aims to explore physicians' self-assessment in intercultural communication in relation to care for patients from diverse ethnic/cultural backgrounds in order to identify training needs of physicians. Subjects and Methods: A descriptive cross-sectional study using self-administered questionnaire filled in by 254 working physician in Jeddah, Kingdom of Saudi Arabia (KSA). A good internal consistency coefficient (Cronbach's alpha) of the questionnaire was obtained. Descriptive statistics were used and ANOVA has been employed for assessing statistical differences between groups. Results: Respondents rated themselves more competent in basic clinical skills with mean score $4.33 \pm 0.58$, then general intercultural skills came next $(3.89 \pm 0.69)$ followed lastly by intercultural communication skills (3.29 \pm 1.00$)$. Regarding intercultural communication skills and general intercultural skills, we found statistically significant differences $(p<0.05)$ in mean scores between respondents with reference to their age group, rank, total duration of work in KSA, previous work experience in other countries than home country and exposure to training in cultural competence. Conclusion: Training in cultural competence is an important factor that leads to better self-rating in intercultural communication skills. Physicians should be provided with real opportunities for training in cultural competence.
\end{abstract}

Keywords: Intercultural communication, Cultural competence, Basic clinical skills

CORRESPONDING AUTHOR Dr. Hani Salem Atwa, Medical Education Department, Faculty of Medicine, Suez Canal University, Ismailia 41611, Egypt | Email: doctorhani2000@yahoo.com

\section{Introduction}

Intercultural communication is often defined as "communication between people from different national cultures" (1). Many scholars limit intercultural communication to face-to-face communication (2).
The relationship between the patient and the health care provider is an essential component of the delivery of health care (3). One of the important issues in the study of this relationship is the relation between patients' ethnic/cultural background and medical communication. The fundamental question raised in this regard is to what 
extent belonging to an ethnic/cultural group influences the communication process between patients and their doctors (4).

If you are working, or going to work, as a physician in the Kingdom of Saudi Arabia, you must be aware of the diverse cultural and linguistic properties of people living there. You will need to know how language and culture can influence your clinical communication with patients and the way you provide care for them, and to have the skills necessary to identify and respond efficiently to patients' diverse needs $(5,6)$.

Residents of the Kingdom of Saudi Arabia (KSA) are either native Saudis $(66 \%$ of the whole population) or non-Saudis from different nationalities and ethnic/cultural backgrounds (34\% of the whole population) (7). This roughly means that one of each three persons seeking medical care is nonSaudi, who may speak a different language and have come from a different cultural background. In addition, the majority of the physicians are non-Saudis $(76 \%$ of practicing physicians) (8). These facts mandate the readiness of physicians to deal effectively with such differences.

Skills of dealing with such multicultural and multilingual patients include (beside the general basic clinical skills) the ability to elicit the patient's understanding of the illness, determine the patient's sociocultural context and identify any issues that might affect care, communicate effectively across patient-provider social and cultural differences, and providing information including giving bad news (9-11).

This study aimed at exploring the physicians' self-assessment in relation to care for patients from diverse ethnic/cultural and linguistic backgrounds in order to identify training needs of physicians.

\section{Subjects and Methods}

The study is a descriptive cross-sectional one. Based on a study by Hudelson et al. (12) and the number of practicing physicians in Jeddah, a sample size of 330 physicians was calculated. As it was difficult to obtain lists of practicing physicians in Jeddah and their contact details, we personally approached the indicated number of physicians in different governmental and private hospitals and health dispensaries all over the regions of central Jeddah. Data collection extended over around 4 months and the response rate was $77 \%(254 ; 175$ males and 79 females).

We used the questionnaire developed by Hudelson et al. (13). Out of the 14 items of the original questionnaire, one item has been removed; which is "Explore the migratory trajectory and possible traumatic experiences of an asylum seeker". This is because it does not apply to the Saudi context. The 'modified' version of the questionnaire is composed of 13 items in three domains: Basic Clinical Skills (6 items), Intercultural Communication Skills (3 items), and General Intercultural Skills (4 items).

Internal consistency coefficients Cronbach's alpha coefficients) of the different subscales of the questionnaire, as well as the questionnaire as a whole, were obtained (Table 1). Based on the selfadministered questionnaire, respondents were asked to rate themselves regarding their perceived competency in different skills pertaining to the three subscales of the questionnaire by choosing a number from 1 to 5 on the 5 -point scale, where 5 means "Most Competent" and 1 means "Least Competent". Data were collected and entered to Microsoft Excel 2010. IBM SPSS v. 20 (14) was used for statistical analysis. 


\section{Data Analysis}

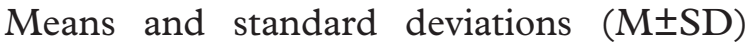
has been calculated for each skill and for the three categories of skills (Basic Clinical Skills, Intercultural Communication Skills, and General Intercultural Skills). For differences between groups, we used analysis of variance (ANOVA) tests. Linear trends were applied for ordinal variables (Age Group, Rank and Total Duration of Work in KSA) and presented as line graphs. Statistical significance was set at $p<0.05$.

\section{Results}

An overall number of 254 respondents were included in the study; $68.9 \%$ were males and $31.1 \%$ were females. Internal consistency was established through Cronbach's alpha coefficient. Table 1 shows good values for internal consistency for each of the questionnaire's subscales. Alpha values ranged from 0.629 for "Intercultural Communication Skills" to 0.806 for "Basic Clinical Skills".

Table 2 shows demographic characteristics of the studied sample. However, it was notable that most of the respondents were non-Saudi (70.9\% non-Saudi Arabic, and $23.2 \%$ non-Saudi non-Arabic).

In addition, only a small percentage of the respondents $(16.9 \%)$ reported that they had previous work experience outside their home countries before coming to Saudi Arabia. Also, a very small percentage $(8.7 \%)$ reported that they have been exposed to any training in cultural competence.

Table 3 shows that, in general, basic clinical skills had a greater mean score $(4.33 \pm 0.58)$ than the other two types of skills. General intercultural skills came next (3.89 \pm 0.69$)$ followed lastly by intercultural communication skills $(3.29 \pm 1.00)$.
Differences in mean scores of selfassessment scales in basic clinical skills were found to be statistically significant $(p$ $<0.05$ ) between respondents as regards age group, rank, total duration in KSA and current workplace (Table 4). In reference to nationality, gender, previous work experience in other countries than home country and exposure to training in cultural competence, differences in mean scores of self-assessment scales in basic clinical skills between respondents were found close with no statistical significance.

Table 1: Internal consistency study of the questionnaire using Cronbach's alpha

\begin{tabular}{cc}
\hline Subscales & Cronbach's alpha \\
\hline Basic Clinical Skills & 0.806 \\
$\begin{array}{c}\text { Intercultural } \\
\text { Communication Skills } \\
\text { General Intercultural } \\
\text { Skills }\end{array}$ & 0.629 \\
\hline
\end{tabular}

Regarding intercultural communication skills (Table 5) and general intercultural skills (Table 6), we found statistically significant differences $(p<0.05)$ in mean scores between respondents with reference to their age group, rank, total duration of work in KSA, previous work experience in other countries than home country and exposure to training in cultural competence. In reference to nationality, gender and current workplace, differences in mean scores of self-assessment scales in intercultural communication skills between respondents were found statistically insignificant.

Mean scores for ordinal data of Age Group (Figure 1), Rank (Figure 2) and Total Duration of Work in KSA (Figure 3) shows linear trend, where the mean scores increase concomitantly with increase in age, progress in rank from resident to consultant, and increase in the duration of work in KSA. 


\section{Discussion}

Although our study aimed at evaluation of the physicians' self-assessment in intercultural communication skills, two other types of skills were also included in our study. Those skills were: basic clinical skills and general intercultural skills. This was because the three types of skills are strongly related. In addition, this was deemed to provide a comprehensive coverage of general skills (both clinical or communication skills) a physician is supposed to perform.

Among the three types of skills, physicians rated themselves best in basic clinical skills, especially in obtaining relevant medical history and performing targeted clinical examination. This was expected, as it touches the core competences of physicians and it is very uncommon that a physician assesses himself as weak in such competences. In addition, physicians are not allowed to practice in KSA until they pass the licensing exams of the Saudi Commission for Health Specialties (15). Similar results were found by Hudelson et al. (12). Also it is noticed that neither previous work experience in other countries nor training in cultural competence affected the self-assessment scores of physicians in their basic clinical skills.

Intercultural communication skills were rated least, especially for the skills of discussing religious preferences in relation to treatment and changing the beliefs of the patients who believe that their illness is due to supernatural causes. This may indicate a problem for the physicians in finding the best technique in convincing patients, may be due to inability to understand the patient's language or cultural backgrounds.

There were minor differences between male and female physicians in all the types of assessed skills. None of those differences was statistically significant; although it was reported by Roter and Hall (16) female clinicians tend to engage in more patientcentered communication.
Progress in age (from young physicians to older ones), in rank (from residents to consultants) and in the total duration of work in KSA were found to be associated with an increase in mean score for selfassessment in all the three types of skills. In addition, having previous work experience in other countries than home country was associated with an increase mean score both in intercultural communication skills and general intercultural skills. This indicates the importance of experience and practice in the progress of clinical skills, as well as in dealing with patients from different cultural and ethnic backgrounds $(2,17)$. However, other authors argued that experience alone without formal training in intercultural communication may negatively affect the attitude of physicians towards multicultural patients $(18,19)$.

In our study, exposure to training in cultural competence was found to cause significant differences in self-assessment mean scores for both intercultural communication skills and general intercultural skills. In their study on intercultural communication competence in family medicine, Rosenberg et al. (20) concluded that providing physicians with formal training in intercultural communication and empowerment training for patients is likely to improve the quality of care of immigrants. Hudelson et al. (12) found similar differences. However, the differences were statistically significant only for intercultural communication skills but not for general intercultural skills.

Although self-assessment is useful in giving an idea about the performance (21-23) and in determining self-confidence in intercultural situations (24-27), which is the case in our study, we cannot depend solely on self-assessment in assessing clinical and communication skills and other objective methods such as OSCE should be used (28, 29).

To the best of our current knowledge, there are no studies in intercultural clinical communication in the Arab region. 
Table 2: Demographic characteristics of the studied sample

\begin{tabular}{|c|c|c|}
\hline \multirow{2}{*}{ Groups } & \multicolumn{2}{|c|}{ Demographics $(n=254)$} \\
\hline & No. & $\%$ \\
\hline \multicolumn{3}{|l|}{ Nationality: } \\
\hline Saudi & 15 & 5.9 \\
\hline Non-Saudi, Arabic & 180 & 70.9 \\
\hline Non-Saudi, Non-Arabic & 59 & 23.2 \\
\hline \multicolumn{3}{|l|}{ Gender: } \\
\hline Male & 175 & 68.9 \\
\hline Female & 79 & 31.1 \\
\hline \multicolumn{3}{|l|}{ Age group: } \\
\hline$\leq 25$ years & 5 & 2.0 \\
\hline $25-40$ years & 75 & 29.5 \\
\hline $41-55$ years & 149 & 58.7 \\
\hline$\geq 56$ years & 25 & 9.8 \\
\hline \multicolumn{3}{|l|}{ Rank: } \\
\hline Resident & 35 & 13.8 \\
\hline Specialist & 99 & 39.0 \\
\hline Consultant & 120 & 47.2 \\
\hline \multicolumn{3}{|l|}{ Total duration of work in KSA: } \\
\hline$\leq 1$ year & 17 & 6.7 \\
\hline $2-5$ years & 101 & 39.8 \\
\hline $6-10$ years & 100 & 39.4 \\
\hline$>10$ years & 36 & 14.2 \\
\hline \multicolumn{3}{|l|}{ Current workplace: } \\
\hline Private & 198 & 78.0 \\
\hline Governmental & 56 & 22.0 \\
\hline \multicolumn{3}{|c|}{ Previous work experience in other countries than home country? } \\
\hline Yes & 43 & 16.9 \\
\hline No & 211 & 83.1 \\
\hline \multicolumn{3}{|l|}{ Training in cultural competence? } \\
\hline Yes & 22 & 8.7 \\
\hline No & 232 & 91.3 \\
\hline
\end{tabular}


Table 3: Mean scores (and standard deviation) for each skill of the self-assessment questionnaire

\begin{tabular}{|c|c|c|}
\hline Skills & Mean & SD \\
\hline Basic Clinical Skills: & 4.33 & 0.58 \\
\hline Obtain a medical history that is relevant to the patient's complaint. & 4.95 & 0.46 \\
\hline Perform a clinical examination that is targeted at the patient's chief complaint. & 4.93 & 0.76 \\
\hline Obtain a psychosocial history from the patient. & 4.37 & 0.28 \\
\hline Announce bad news (e.g., an unfavorable prognosis). & 3.47 & 0.77 \\
\hline $\begin{array}{l}\text { Make sure that an illiterate patient understands the treatment of his chronic } \\
\text { disease (e.g., hypertension, depression, etc.). }\end{array}$ & 3.88 & 0.84 \\
\hline $\begin{array}{l}\text { Explain the reason for refusing an unjustified treatment or investigation to } \\
\text { patient who requests it. }\end{array}$ & 4.35 & 0.39 \\
\hline Intercultural Communication Skills: & 3.29 & 0.69 \\
\hline $\begin{array}{l}\text { Discuss advantages and risks of unconventional therapies with a patient who } \\
\text { uses them. }\end{array}$ & 3.69 & 0.77 \\
\hline $\begin{array}{l}\text { Discuss a patient's religious preferences and constraints regarding his } \\
\text { treatment. }\end{array}$ & 3.17 & 0.64 \\
\hline $\begin{array}{l}\text { Communicate the importance of medical treatment to a patient who believes } \\
\text { that his illness is due to supernatural causes. }\end{array}$ & 3.02 & 0.67 \\
\hline General Intercultural Skills: & 3.89 & 1.00 \\
\hline Work effectively with a professional interpreter. & 3.91 & 1.05 \\
\hline Orient a foreign patient toward appropriate medical and social services. & 3.85 & 0.76 \\
\hline Perform a physical examination of a Muslim woman who wears a veil. & 3.57 & 1.19 \\
\hline $\begin{array}{l}\text { Ask questions and give information to the husband of a patient, if she } \\
\text { requests it. }\end{array}$ & 4.22 & 1.01 \\
\hline
\end{tabular}

Table 4: Mean scores and comparisons of self-assessment in basic clinical skills

\begin{tabular}{llc} 
& Groups & \multicolumn{2}{c}{ Univariate Comparison } \\
\cline { 2 - 3 } & Mean (SD) & p-value \\
\hline Nationality: & & \\
Saudi & $4.35(0.43)$ & \\
Non-Saudi, Arabic & $4.42(0.62)$ & 0.164 \\
$\quad$ Non-Saudi, Non-Arabic & $4.24(0.70)$ & \\
Gender: & & \\
Male & $4.32(0.62)$ & 0.621 \\
$\quad$ Female & $4.36(0.54)$ & \\
Age group: & & \\
$\quad \leq 25$ years & $4.03(0.57)$ & \\
25-40 years & $4.15(0.78)$ & $0.001^{*}$ \\
41-55 years & $4.47(0.55)$ & \\
$\quad$ 256 years & $4.55(0.45)$ & \\
Rank: & & \\
Resident & $3.97(0.53)$ & \\
Specialist & $4.58(0.58)$ & $0.000^{*}$ \\
$\quad$ Consultant & $4.52(0.63)$ & \\
\hline
\end{tabular}


Table 4: (continued)

\begin{tabular}{|c|c|c|}
\hline \multirow{2}{*}{ Groups } & \multicolumn{2}{|c|}{ Univariate Comparison } \\
\hline & Mean (SD) & p-value \\
\hline \multicolumn{3}{|l|}{ Total duration of work in KSA: } \\
\hline$\leq 1$ year & $3.61(0.42)$ & \multirow{4}{*}{$0.000^{*}$} \\
\hline $2-5$ years & $4.42(0.57)$ & \\
\hline $6-10$ years & $4.54(0.77)$ & \\
\hline$>10$ years & $4.76(0.59)$ & \\
\hline \multicolumn{3}{|l|}{ Current workplace: } \\
\hline Private & $4.43(0.52)$ & \multirow{2}{*}{$0.023^{*}$} \\
\hline Governmental & $4.24(0.64)$ & \\
\hline \multicolumn{3}{|c|}{ Previous work experience in other countries than home country? } \\
\hline Yes & $4.35(0.50)$ & \multirow{2}{*}{0.634} \\
\hline No & $4.30(0.65)$ & \\
\hline \multicolumn{3}{|c|}{ Training in cultural competence? } \\
\hline Yes & $4.31(0.54)$ & \multirow{2}{*}{0.824} \\
\hline No & $4.34(0.61)$ & \\
\hline
\end{tabular}

Table 5: Mean scores and comparisons of self-assessment in intercultural communication skills

\begin{tabular}{|c|c|c|}
\hline \multirow{2}{*}{ Groups } & \multicolumn{2}{|c|}{ Univariate Comparison } \\
\hline & Mean (SD) & $p$-value \\
\hline \multicolumn{3}{|l|}{ Nationality: } \\
\hline Saudi & $3.31(0.51)$ & \multirow{3}{*}{0.462} \\
\hline Non-Saudi, Arabic & $3.36(0.74)$ & \\
\hline Non-Saudi, Non-Arabic & $3.22(0.83)$ & \\
\hline \multicolumn{3}{|l|}{ Gender: } \\
\hline Male & $3.28(0.74)$ & \multirow{2}{*}{0.746} \\
\hline Female & $3.31(0.64)$ & \\
\hline \multicolumn{3}{|l|}{ Age group: } \\
\hline$\leq 25$ years & $3.06(0.78)$ & \multirow{4}{*}{$0.048^{*}$} \\
\hline $25-40$ years & $3.15(0.93)$ & \\
\hline $41-55$ years & $3.42(0.65)$ & \\
\hline$\geq 56$ years & $3.45(0.54)$ & \\
\hline \multicolumn{3}{|l|}{ Rank: } \\
\hline Resident & $3.02(0.63)$ & \multirow{3}{*}{$0.006^{*}$} \\
\hline Specialist & $3.45(0.69)$ & \\
\hline Consultant & $3.43(0.75)$ & \\
\hline \multicolumn{3}{|l|}{ Total duration of work in KSA: } \\
\hline$\leq 1$ year & $2.74(0.49)$ & \multirow{3}{*}{$0.002^{*}$} \\
\hline $\begin{array}{l}2-5 \text { years } \\
6-10 \text { years }\end{array}$ & $3.36(0.68)$ & \\
\hline$>10$ years & $\begin{array}{l}3.45(0.92) \\
3.62(0.70)\end{array}$ & \\
\hline \multicolumn{3}{|l|}{ Current workplace: } \\
\hline Private & $3.37(0.62)$ & \multirow{2}{*}{0.130} \\
\hline Governmental & $3.22(0.76)$ & \\
\hline
\end{tabular}


Table 5: (continued)

\begin{tabular}{ccc}
\hline \multirow{2}{*}{ Groups } & \multicolumn{2}{c}{ Univariate Comparison } \\
\cline { 2 - 3 } & Mean (SD) & p-value \\
\hline $\begin{array}{c}\text { Previous work experience in other countries than home country? } \\
\text { Yes }\end{array}$ & $3.51(0.48)$ & $0.001^{*}$ \\
No & $3.06(0.89)$ & \\
Training in cultural competence? & & \\
Yes & $3.62(0.63)$ & $0.000^{*}$ \\
No & $2.94(0.74)$ & \\
\hline
\end{tabular}

Table 6: Mean scores and comparisons of self-assessment in general intercultural skills

\begin{tabular}{|c|c|c|}
\hline \multirow{2}{*}{ Groups } & \multicolumn{2}{|c|}{ Univariate Comparison } \\
\hline & Mean (SD) & $p$-value \\
\hline \multicolumn{3}{|l|}{ Nationality: } \\
\hline Saudi & $3.91(0.74)$ & \multirow{3}{*}{0.618} \\
\hline Non-Saudi, Arabic & $3.97(1.07)$ & \\
\hline Non-Saudi, Non-Arabic & $3.81(1.21)$ & \\
\hline \multicolumn{3}{|l|}{ Gender: } \\
\hline Male & $3.88(1.07)$ & \multirow{2}{*}{0.774} \\
\hline Female & $3.92(0.93)$ & \\
\hline \multicolumn{3}{|l|}{ Age group: } \\
\hline$\leq 25$ years & $3.42(0.98)$ & \multirow{4}{*}{$0.000^{*}$} \\
\hline $25-40$ years & $3.53(1.34)$ & \\
\hline $41-55$ years & $4.22(0.95)$ & \\
\hline$\geq 56$ years & $4.29(0.78)$ & \\
\hline \multicolumn{3}{|l|}{ Rank: } \\
\hline Resident & $3.57(0.91)$ & \multirow{3}{*}{$0.024^{*}$} \\
\hline Specialist & $4.11(1.00)$ & \\
\hline Consultant & $4.06(1.09)$ & \\
\hline \multicolumn{3}{|l|}{ Total duration of work in KSA: } \\
\hline$\leq 1$ year & $3.24(0.72)$ & \multirow{4}{*}{$0.014^{*}$} \\
\hline $2-5$ years & $3.97(0.98)$ & \\
\hline $6-10$ years & $4.08(1.33)$ & \\
\hline$>10$ years & $4.28(1.02)$ & \\
\hline \multicolumn{3}{|l|}{ Current workplace: } \\
\hline Private & $3.98(0.89)$ & \multirow{2}{*}{0.233} \\
\hline Governmental & $3.81(1.10)$ & \\
\hline \multicolumn{3}{|c|}{ Previous work experience in other countries than home country? } \\
\hline Yes & $4.17(0.69)$ & \multirow{2}{*}{$0.007^{*}$} \\
\hline No & $3.62(1.29)$ & \\
\hline \multicolumn{3}{|l|}{ Training in cultural competence? } \\
\hline Yes & $4.21(0.91)$ & \multirow{2}{*}{$0.007^{*}$} \\
\hline No & $3.57(1.07)$ & \\
\hline
\end{tabular}




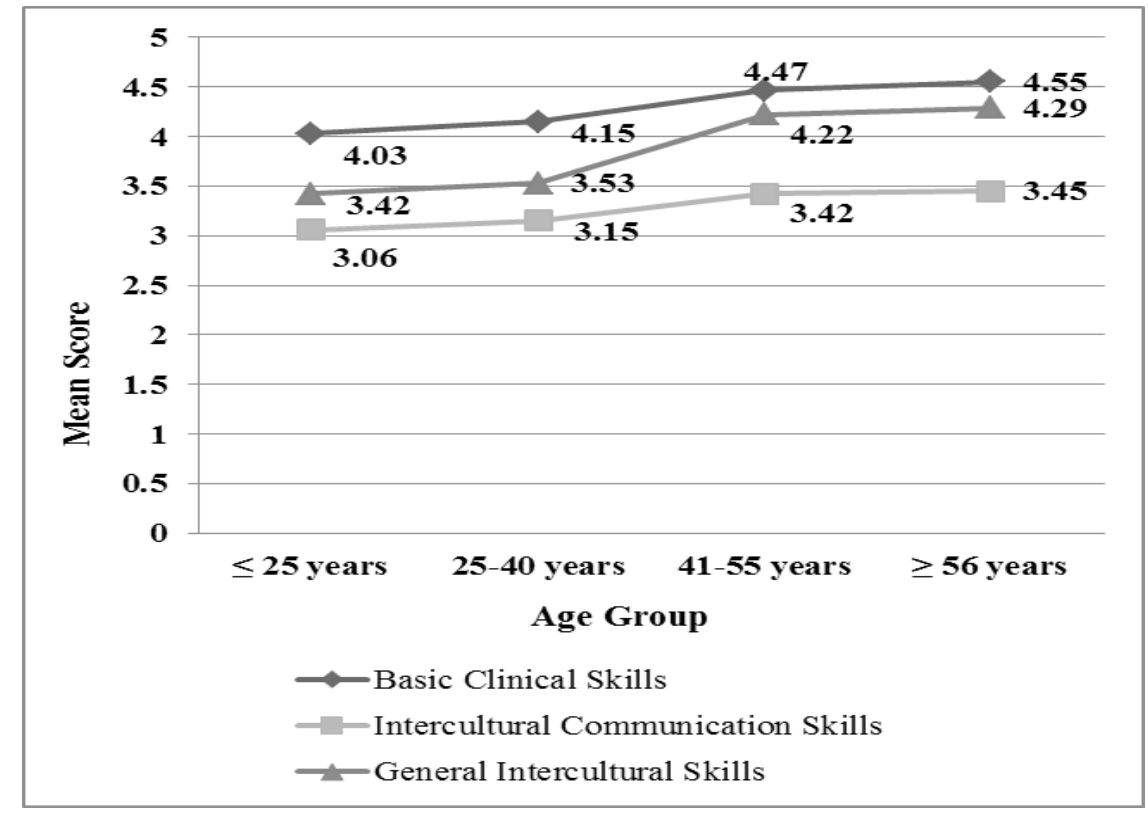

Figure 1: Linear trend of "Age Groups" variable

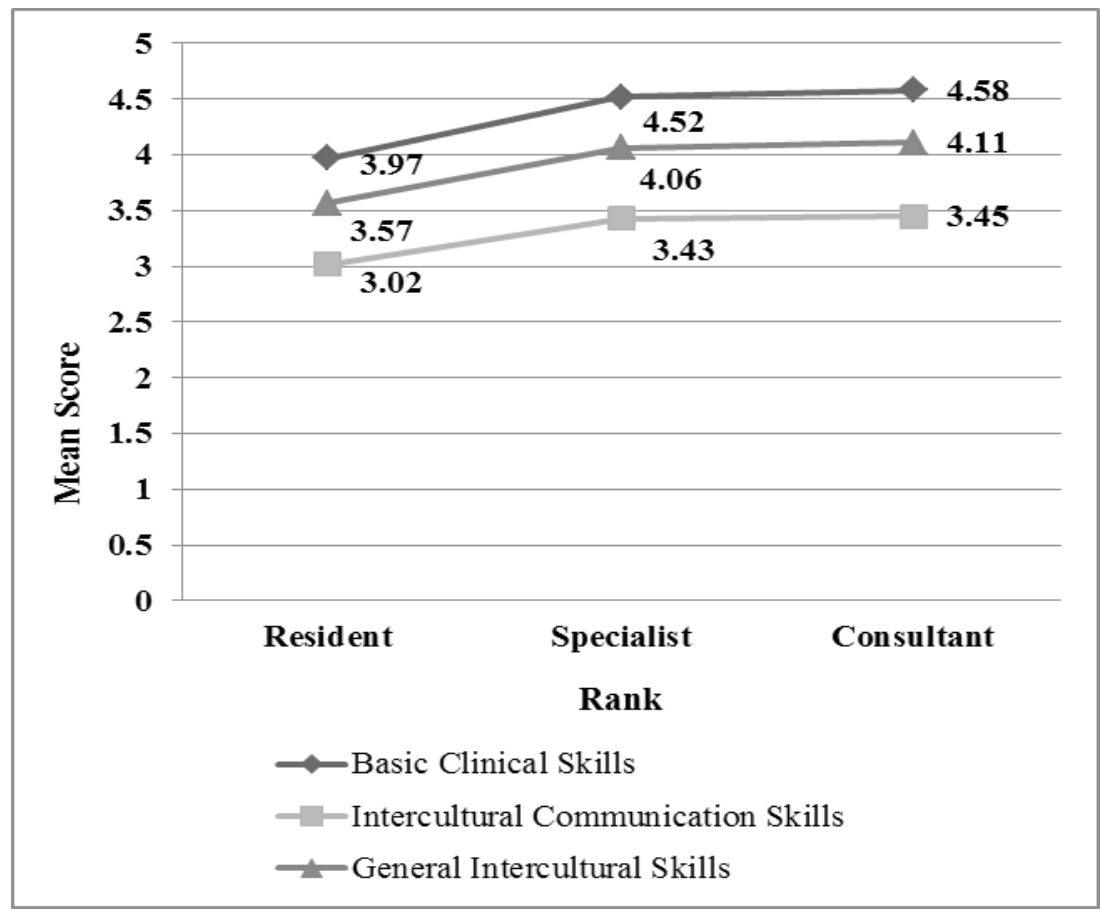

Figure 2: Linear trend of "Rank" variable 


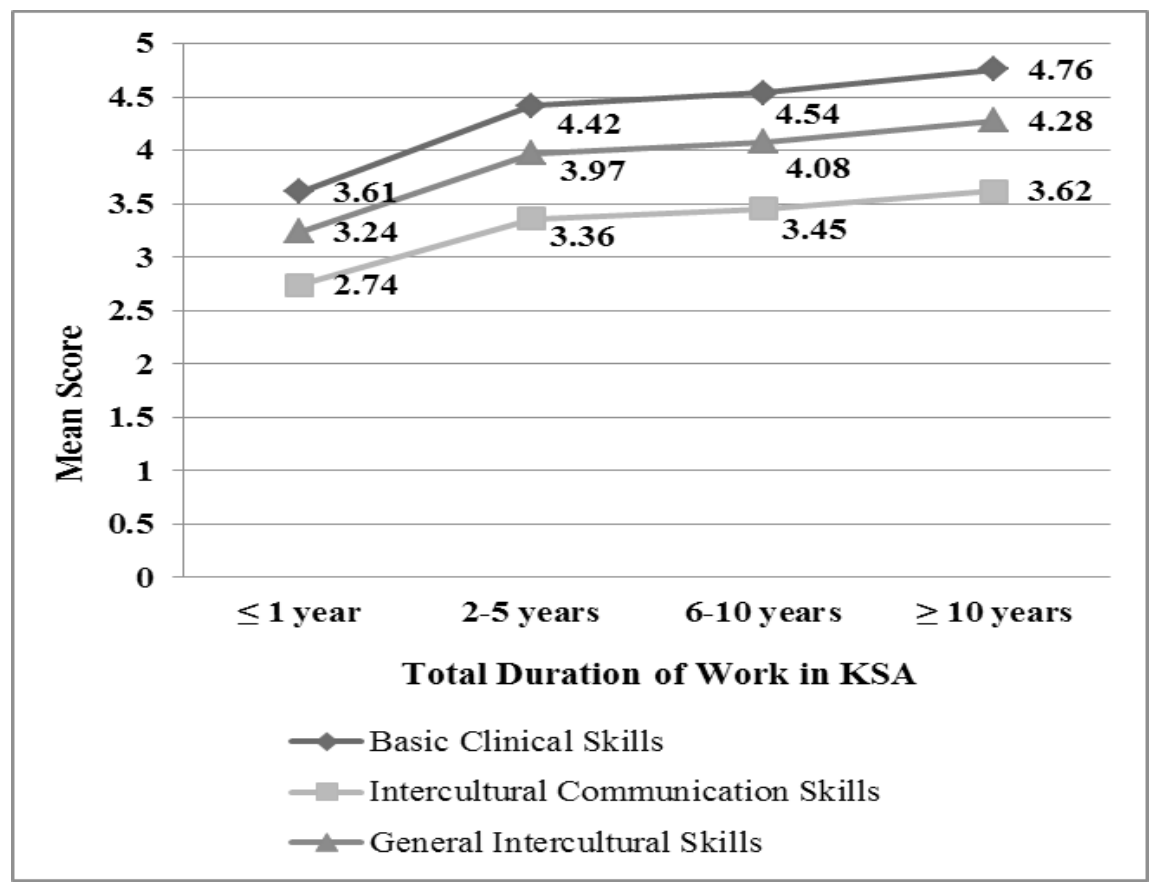

Figure 3: Linear trend of "Total Duration of Work in KSA" variable

Although this gave value to our study, we report that our study has some limitations, among which are: inadequate sampling and data collection techniques, restriction of the study to the region of Jeddah that may not be representative of all physicians in the Saudi health system and restriction of the study methods to self-assessment. We recommend addressing this important issue in a nation-wide, large scale study that uses different objective assessment methods of the intercultural communication competences in addition to self-assessment.

\section{Conclusion}

Training in cultural competence is among the important factors that lead to better self-rating in intercultural communication skills. Practicing physicians should not depend only on experience in gaining and improving their intercultural communication skills, but also they should be provided with real opportunities for training on such skills. That training should start formally while they are in the undergraduate stage at medical schools. Furthermore, as long as they are working with different patients from different cultural and national backgrounds, they should always seek opportunities for continuing professional development in this field.

Self-assessment in our study succeeded to give us an idea about performance of physicians in intercultural communication skills, but the assessment results can only be depended upon when mixed with objective methods of assessment of physicians in such skills.

\section{Acknowledgements}

We express our sincere thanks to the physicians who participated in the study.

\section{References}

1. Gudykunst W. Intercultural communication. In: W. B. Gudykunst, B. Mody, editors. Handbook of international and intercultural communication. Thousand Oaks, CA: Sage; 2002. p. 179-182. 
2. Arasaratnam L, Doerfel M. Intercultural communication competence: identifying key components from multicultural perspectives. International Journal of Intercultural Relations. 2005;29:137-163. doi: 10.1016/j. ijintrel.2004.04.001.

3. Street RL Jr., Millay B. Analyzing patient participation in medical encounters. Health Communication. 2001;13:61-73. doi: 10.1207/S15327027HC1301_06.

4. Schouten B, Meeuwesen L. Cultural differences in medical communication: a review of the literature. Patient Education and Counseling. 2006;64:21-34. doi: 10.1016/j.pec.2005.11.014

5. Betancourt J, Green A, Carrillo J. The challenges of cross-cultural healthcarediversity, ethics, and the medical encounter. Bioethics Forum. 2000;16(3):27-32.

6. Lingard L, Tallett S, Rosenfield J. Culture and physician-patient communication: a qualitative exploration of residents' experiences and attitudes. Annals of the Royal College of Physicians and Surgeons of Canada. 2002;35(6):331-335.

7. General Authority for Statistics [Internet]. Kingdom of Saudi Arabia: General Authority for Statistics, c2016 [cited 2015 November 19]. Saudi Central Department of Statistics and Information; Available from: http://www. cdsi.gov.sa/

8. Ministry of Health Portal [Internet]. Kingdom of Saudi Arabia: Ministry of Health, 2014 [cited 2015 November 19]. Saudi Ministry of Health Annual Statistical Book; Available from: http://www.moh.gov. sa/ministry/statistics/book/pages/default.aspx.

9. American Institutes for Research. Teaching cultural competence in health care: a review of current concepts, policies and practices. Report prepared for the Office of Minority Health. Washington, DC: Author; 2002. Available from: http://minorityhealth.hhs. gov/assets/pdf/checked/1/em01garcia1.pdf

10. Betancourt JR, Green AR, Carrillo JE, Ananeh-Firempong O. Defining cultural competence: a practical framework for addressing racial/ethnic disparities in health and health care. Public Health Reports. 2003;118(4):293-302. doi: 10.1016/S00333549(04)50253-4.

11. Tervalon M. Components of culture in health for medical students' education. Academic Medicine. 2003;78(6):570-576. doi: 10.1097/00001888-200306000-00005.

12. Hudelson P, Perron N, Perneger T. Selfassessment of intercultural communication skills: a survey of physicians and medical students in Geneva, Switzerland. BMC Medical Education. 2001;11:63. doi: 10.1186/1472-6920-11-63.

13. Hudelson P, Perron N, Perneger T. Measuring physicians' and medical students' attitudes toward caring for immigrant patients. Evaluation \& The Health Professions. 2010;33(4):452-472. doi: $10.1177 / 0163278710370157$.

14. IBM: SPSS Statistics version 20. [CD-Rom] Chicago, IL, 2012.

15. Saudi Commission for Health Specialties [Internet]. Kingdom of Saudi Arabia: Saudi Commission for Health Specialties; c2016 [cited 2016 January 9]. Available from: http://www.schhs.org.sa/en/pages/index.aspx.

16. Roter D, Hall J. Physician gender and patient-centered communication: a critical review of empirical research. Annual Review of Public Health. 2004;25:497-519. doi: 10.1146/annurev. publhealth.25.101802.123134.

17. Hudelson P. Improving patient-provider communication: insights from interpreters. Family Practice. 2005;22(3):311-316. doi: 10.1093/fampra/cmi015.

18. Wear D, Kuczewski M. Perspective: medical students' perceptions of the poor: what impact can medical education have? Academic Medicine. 2008;83(7):639-645. doi: 10.1097/ACM.0b013e3181782d67.

19. Lie D, Shapiro J, Cohn F, Najm W. Reflective practice enriches clerkship students' cross- 
cultural experiences. Journal of General Internal Medicine. 2010;25(Suppl 2):S119125. doi: 10.1007/s11606-009-1205-4.

20. Rosenberg E, Richard C, Lussier M-T, Abdool S. Intercultural communication competence in family medicine: lessons from the field. Patient Education and Counseling. 2006;61:236-245. doi: 10.1016/j. pec.2005.04.002.

21. Ho M, Lee K, Green A. Can cultural competency self-assessment predict OSCE performance? Medical Education. 2008;42(5):525. doi: $10.1111 / j .1365-$ 2923.2008.03048.x.

22. Silver I, Campbell C, Marlow B, Sargeant J. Self-assessment and continuing professional development: the Canadian perspective. The Journal of Continuing Education in the Health Professions. 2008;28(1):25-31. doi: 10.1002/chp.152.

23. Pisklakov S, Rimal J, McGuirt S. Role of self-evaluation and self-assessment in medical student and resident education. British Journal of Education, Society \& Behavioural Science. 2014;4(1):1-9. doi: 10.9734/BJESBS/2014/5066.

24. Shapiro J, Hollingshead J, Morrison E. Selfperceived attitudes and skills of cultural competence: a comparison of family medicine and internal medicine residents. Medical Teacher. 2003;25(3):327-329. doi: $10.1080 / 0142159031000100454$.
25. Gozu A, Beach MC, Price EG, Gary TL, Robinson K, Palacio A, et al. Selfadministered instruments to measure cultural competence of health professionals: a systematic review. Teaching and Learning in Medicine. 2007;19(2):180-190. doi: $10.1080 / 10401330701333654$.

26. Park E, Chun M, Betancourt J, Green A, Weissman J. Measuring residents' perceived preparedness and skillfulness to deliver crosscultural care. Journal of General Internal Medicine. 2009;24(9):1053-1056. doi: 10.1007/s11606-009-1046-1.

27. Jeffreys M, Dogan E. Factor analysis of the transcultural self-efficacy tool (TSET). Journal of Nursing Measurement. 2010;18(2):120-139. doi: 10.1891/10613749.18.2.120.

28. Davis D, Mazmanian P, Fordis M, Van Harrison R, Thorpe K, Perrier L. Accuracy of physician self-assessment compared with observed measures of competence: a systematic review. JAMA. 2006;296(9):1094-1102. doi: 10.1001/ jama.296.9.1094.

29. Green A, Miller E, Krupat E, White A, Taylor W, Hirsh D, et al. Designing and implementing a cultural competence OSCE: lessons learned from interviews with medical students. Ethnicity and Disease. 2007;17(2):344-350. 